\title{
Aging and Human Hormonal and Pressor Responsiveness to Angiotensin II Infusion With Simultaneous Measurement of Exogenous and Endogenous Angiotensin II
}

\author{
Joseph Duggan, Juerg Nussberger, S. Kilfeather, and K. O'Malley
}

A decline in the function of the renin angiotensin aldosterone system may induce adaptive changes in response to angiotensin II (ANG II) with age. We have examined platelet ANG II receptor density, blood pressure and aldosterone responses to ANG II [Asn ${ }^{1}$, Val$^{5}$-ANG II] (Hypertensin, Ciba Geigy, Horsham, Sussex, England) infusion in 8 young, 24 to 30 years, and 8 older, 54 to 65 years, healthy volunteers. To measure circulating ANG II, we established a new method for specific and simultaneous measurement of exogenous [Asn $\left.{ }^{1}, \mathrm{Val}^{5}\right]$ (Hypertensin) and endogenous $\left[\mathrm{Asp}^{1}, \mathrm{Ile}^{5}\right]$ ANG II in plasma by using isocratic HPLC and radioimmunoassays with cross-reacting antibodies and compared results with immunoreactive ANG II which was measured conventionally using monoclonal antibodies.

Baseline endogenous ANG II (Asp' ${ }^{\mathbf{1}}$ Ile $^{\mathbf{5}}$-ANG II) levels in venous plasma were marginally, but not significantly, lower in the old [mean $(95 \%$ confidence limits): 3.4 ( $<0.1$ to 7.7$) v 3.7$ (1.2 to 6.2$)$, fmol/ $\mathrm{mL}]$ and during suppression by the Hypertensin infusion appeared consistently, but not significantly, lower in the old [0.9 (0 to 3.1) $v 2.1$ (0.6 to 3.7), after 3 $\mathrm{ng} / \mathrm{kg} / \mathrm{min}$ ], while the same infusion rate in young and old resulted in similar plasma Hypertensin levels. Baseline systolic blood pressure (SBP) was similar in both groups but the percentage increases in SBP at infusion rates of $1,3.0$, and $10 \mathrm{ng} / \mathrm{kg} / \mathrm{min}$ were greater in the old than in the young (9.1 $v 2.8$,

Received October 15, 1992. Accepted April 13, 1993.

From the Department of Clinical Pharmacology, Royal College of Surgeons in Ireland, Dublin, Ireland (JD, SK, KOM), and Division of Hypertension, University Hospital, Lausanne, Switzerland (JN).

Address correspondence and reprint requests to Dr. J. Duggan, Department of Geriatric Medicine, University Hospital of South Manchester, Manchester, M20 8LR, England.
$P<.05 ; 16.3 v 8.0, P<.01 ; 30.4 v 14.0 \%, P<.001$, respectively). The increment in diastolic blood pressure or mean arterial pressure during infusion did not differ significantly between the groups. Heart rate fell significantly during ANG II infusion in young $(P<.05)$ but not old subjects. Basal plasma aldosterone was similar in both groups. However, the percentage increases in plasma aldosterone were greater in young than old at infusion rates of $1.0,3.0$, and $10.0 \mathrm{ng} / \mathrm{kg} / \mathrm{min}(94 v-5 ; 238 v 28 ; 462$ $v 69 \%$, all $P<.001)$. Platelet ANG II receptor density was elevated in the old [6.5 (1.9 to 11.1) $v$ 1.14 (0.21 to 2.07), fmol/109 cells, $P<.01]$.

Our findings demonstrate that it is possible to measure specifically and simultaneously exogenous and endogenous ANG II in plasma during Hypertensin infusion and that endogenous ANG II concentrations decrease with increasing levels of exogenous ANG II. During infusion, similar plasma Hypertensin levels were attained in both young and old, but systolic blood pressure responsiveness was increased in the old, while adrenal responsiveness was reduced. Am J Hypertens 1993;6:641 - 647

KEY WORDS: Age, angiotensin II infusion, blood pressure, aldosterone, HPLC, radioimmunoassay, platelet angiotensin II receptor density, $\mathrm{Asn}^{1}{ }^{1} \mathrm{Val}^{\mathbf{5}_{-}}$ angiotensin II (Hypertensin). 
particular, there is a decline in the function of the RAAS with age ${ }^{4-7}$ with a well documented fall in both plasma renin activity (PRA) and aldosterone. Since PRA and ANG II correlate closely, ${ }^{8}$ it is conceivable that plasma ANG II would also decline with age and contribute to falling plasma aldosterone with age. A fall in plasma ANG II could also result in adaptive changes in receptor density or responsiveness in vascular smooth muscle or adrenal zona glomerulosa since circulating plasma ANG II regulates its vascular smooth muscle, platelet, and adrenal zona glomerulosa receptors. ${ }^{9-12}$ In particular, sodium loading which results in a fall in plasma ANG II is associated with an increase in both rat vascular smooth muscle ${ }^{11}$ and human platelet ${ }^{12}$ ANG II receptor density, but a decrease in adrenal zona glomerulosa ANG II receptor density in the rat. ${ }^{9,10}$ Furthermore, there is some evidence to suggest that responses to ANG II infusion in humans are altered with aging which results in increased blood pressure but reduced aldosterone responses to ANG II infusion. ${ }^{13,14}$ There appears, therefore, to be an apparent similarity between receptor density changes under conditions of low circulating ANG II and reported changes in pressor and aldosterone responses to ANG II infusion with aging in humans. The purpose of the present study was to investigate the effect of age on blood pressure, heart rate, plasma endogenous ANG II [Asp ${ }^{1}, \mathrm{Ile}^{5}-\mathrm{ANG}$ II] and aldosterone responses to ANG II [Asn ${ }^{1}, \mathrm{Val}^{5}$-ANG II] (Hypertensin Ciba Geigy, Horsham, Sussex, England) infusion in normal human subjects and also to measure their platelet ANG II receptor density. Conventional ANG II measurement provides only immunoreactive ANG II (irANG II) levels and cannot distinguish between exogenous and endogenous ANG II. We developed an HPLC-based method which allowed us to monitor simultaneously these two peptides by separate measurement within the same plasma sample and to compare these results with conventionally estimated irANG II concentrations.

\section{METHODS}

Subjects Eight young (age range 24 to 30 years; 1 female and 7 male) and eight older (54 to 65 years; 1 female and 7 male) normotensive healthy subjects were studied. All subjects had a normal physical examination, hematological and biochemical screen, and electrocardiogram and none were taking medication. The study was conducted at the Clinical Investigation Unit, Beaumont Hospital and was approved by the hospital Ethical Committee and by the National Drugs Advisory Board. All subjects gave written informed consent.

Study Design Subjects remained on their normal diet on the days prior to study. Sodium status was assessed by a $24 \mathrm{~h}$ urine collection conducted the preceding day. On the morning of infusion they ate a modest breakfast, abstained from caffeinated beverages, and had abstained from cigarette smoking since 21:00 the previous evening. At 09:00 subjects lay supine and an intravenous cannula was sited in a forearm vein in each arm; one for infusion, the other for blood sampling. A control infusion of $5 \%$ dextrose was infused at $10 \mathrm{~mL} / \mathrm{h}$ for 60 min via an infusion pump (Braun perfusor, Germany). Blood pressure was measured at 3 min intervals by an indirect automated sphygmomanometer (Vitastat 900D). A cardiac monitor with visual display recorded heart rate throughout the study.

At the end of the $60 \mathrm{~min}$ control period, basal blood samples were withdrawn for measurement of plasma ANG II, aldosterone, urea, electrolytes, and platelet ANG II receptor density. A graded infusion of ANG II [Asn ${ }^{1}$, Val $^{5}$ ]ANG-(1 - 8)octapeptide (Hypertensin, Ciba Geigy Pharmaceuticals, Horsham, Sussex, England) in $5 \%$ dextrose was commenced at $0.3,1.0,3.0$, and 10 $\mathrm{ng} / \mathrm{kg} / \mathrm{min}$, each dose infused for $30 \mathrm{~min}$. A blood sample was withdrawn at the end of each infusion period for plasma ANG II and aldosterone. All blood samples were taken in prechilled tubes, immediately placed on ice, and centrifuged at $4^{\circ} \mathrm{C}$. Plasma was removed, placed in prechilled cryotubes which were frozen in liquid nitrogen and stored at $-80^{\circ} \mathrm{C}$ until assayed.

Biochemical Measurements Plasma levels of endogenous ANG II and Hypertensin were measured by modification of a previously described standard method..$^{15}$ Blood samples were drawn as originally described on an inhibitor solution containing EDTA, 0 -phenanthroline and neomycin but no renin inhibitor. ${ }^{16}$ The original extraction procedure yielded consistently $>95 \%$ recoveries of Hypertensin added to plasma in picomolar concentrations as used in the present infusion experiments. Overall recoveries (including HPLC) were also virtually complete $(>90 \%)$. Isocratic separation of the different ANG II peaks was obtained with $27 \%$ methanol in the mobile phase: the retention times being $4.3 \mathrm{~min}$ and 9.9 min for Hypertensin and endogenous ANG II respectively. Cross-reaction of the ANG II antiserum with $\mathrm{Hy}$ pertensin was $56 \%$. Total immunoreactive ANG II was measured with a monoclonal antibody which we had produced by the somatic cell fusion technique ${ }^{17}$ and exogenous cross-reacting (13.6\%) Hypertensin was subtracted to obtain endogenous immunoreactive ANG II (ir-ANG II). This was done to investigate, by a different method, the feedback suppression of the renin angiotensin system during Hypertensin infusion. Ir-ANG II is the sum of true ANG II and all the cross-reacting angiotensin peptides. ${ }^{18}$ No angiotensin peptide crossreacted more than $105 \%$ (ANG III). ${ }^{17}$

Platelet ANG II receptor density and affinity were measured as previously described ${ }^{19}$ using a modification of the method described by Mann and colleagues. ${ }^{20}$ Plasma aldosterone was measured by radioimmunoas- 
TABLE 1. BASELINE CLINICAL AND BIOCHEMICAL CHARACTERISTICS OF YOUNG AND ELDERLY GROUPS

\begin{tabular}{|c|c|c|}
\hline & Young & Elderly \\
\hline Age, years & $27.5(25.3-29.7)$ & $59.6(57.1-62.1)$ \\
\hline Weight, kg & $69.6(59.4-79.8)$ & $76.3(65.1-87.5)$ \\
\hline Heart rate, beats $/ \mathrm{min}$ & $63.9(54.8-73.0)$ & $59.2(52.9-65.5)$ \\
\hline \multicolumn{3}{|l|}{ Blood pressure, $\mathrm{mm} \mathrm{Hg}$} \\
\hline Systolic & $113.8(106-121)$ & $115.6(110-122)$ \\
\hline Diastolic & $66.0(58.6-73.4)$ & $81.5(75.6-87.4)^{*}$ \\
\hline Mean & $81.7(76.3-87.1)$ & $92.9(88.2-97.6)^{*}$ \\
\hline \multicolumn{3}{|l|}{ Platelet ANG II receptor } \\
\hline Density, fmol $/ 10^{9}$ cells & $1.14(0.21-2.07)[7]$ & $6.5(1.9-11.1) \dagger[7]$ \\
\hline Affinity, $\left[\mathrm{K}_{\mathrm{d}}\right] \mathrm{pmol} / \mathrm{L}$ & $66.7(32.5-101)[7]$ & $81.2(55.7-107)[7]$ \\
\hline Plasma ANG II, fmol/mL & $3.7(1.2-6.2)$ & $3.4(0-7.7)[4]$ \\
\hline Plasma aldosterone, $\mathrm{pg} / \mathrm{mL}$ & $50.4(42.3-58.5)$ & $55.9(29.4-82.4)$ \\
\hline Urinary sodium, $\mathrm{mmol} / 24 \mathrm{~h}$ & $153(111-194)$ & $175(113-237)$ \\
\hline Urinary potassium, $\mathrm{mmol} / 24 \mathrm{~h}$ & $78.1(47.9-108)$ & $82.2(48.8-116)$ \\
\hline Serum sodium, $\mathrm{mmol} / \mathrm{L}$ & $141(140-142)$ & $140(138-142)$ \\
\hline Serum potassium, mmol/L & $4.5(4.2-4.8)$ & $4.3(4.1-4.5)$ \\
\hline
\end{tabular}

Mean $\left(95 \%\right.$ confidence limits), ${ }^{*} \mathrm{P}<.001, \dagger \mathrm{P}<.01$, elderly compared to young, $n=8$ unless otherwise indicated in square brackets.

say. ${ }^{21}$ Plasma and urinary electrolytes were measured by standard automated methods.

Blood Pressure and Heart Rate Responses To allow time for plasma ANG II levels to reach steady state, ${ }^{22}$ blood pressure and heart rate readings recorded during the first $10 \mathrm{~min}$ following a change in infusion dose were not included in the analysis.

Statistical Analysis All results are expressed as means with $95 \%$ confidence limits. Student's unpaired $t$ test was used to examine differences in basal values between the two age groups. Two factor analyses of variance (ANOVA) with repeated measures on the time factor were used to examine the changes in response to ANG II infusion. Normal distributions were assumed for most variables; where skewed distributions were identified, natural logarithms were used to convert the data to normal. All analyses were carried out using the raw or logarithmic data, but some findings have been expressed as percentage changes in mean values to highlight important group differences. Statistical significance was taken at the conventional $5 \%$ level.

\section{RESULTS}

Baseline clinical, hormonal, and receptor characteristics of both groups are shown in Table 1. Young and old groups did not differ significantly in their mean body weight, serum or urinary electrolytes, basal heart rate, systolic blood pressure, or basal plasma aldosterone. The $24 \mathrm{~h}$ urinary sodium did not influence basal hormone levels in either group. Baseline diastolic and mean arterial pressures as well as platelet ANG II receptor density were significantly higher in old than young. There was a negative correlation between platelet ANG II receptor density and the increase in aldosterone in response to Hypertensin infusion $(\mathrm{r}=-0.61, P=.035)$ and a positive correlation with the increase in systolic blood pressure although this failed to reach statistical significance $(r=0.51, P=.065)$.

Hypertensin infusion resulted in significant increases in plasma Hypertensin levels in both groups $(P<.001$, Figure 1, upper panel). The increases in plasma Hypertensin level did not differ significantly between the young and old subjects $(P=.669)$. Mean $(95 \%$ confidence limits) baseline endogenous ANG II level was marginally, but not significantly, lower in the old group than in the young group $[3.4(<0.1$ to 7.7$) v 3.7(1.2$ to $6.2), \mathrm{fmol} / \mathrm{mL}$, respectively]. These were suppressed significantly $(P<.001)$ to 0.9 (0 to 3.1$)$ and $2.1(0.6$ to 3.7) respectively by the infusion of Hypertensin at a rate of $3 \mathrm{ng} / \mathrm{kg} / \mathrm{min}$; similar levels of suppression were observed at an infusion rate of $10 \mathrm{ng} / \mathrm{kg} / \mathrm{min}$ (Figure 1, middle panel). Mean endogenous ANG II levels were lower in the old throughout the Hypertensin infusion but the differences between the groups were not statistically significant $(P=.775)$. A similar decrease in endogenous ir-ANG II was found during Hypertensin infusion when cross-reacting (and specifically quantitated) Hypertensin levels were subtracted from total irANG II which was measured directly (without HPLC) with monoclonal antibodies. Again, however, there was no difference between the age groups $(P=.486$; Figure 1 , lower panel).

Systolic (SBP), diastolic (DBP), and mean arterial (MAP) pressures all increased significantly in both groups in response to Hypertensin infusion (Figure 2). The increase in SBP relative to baseline was significantly greater in the old than in the young subjects at infusion rates of $1(P<.05), 3(P<.01)$ and $10(P<.001) \mathrm{ng} /$ $\mathrm{kg} / \mathrm{min}$. The increments in DBP and MAP during Hy- 

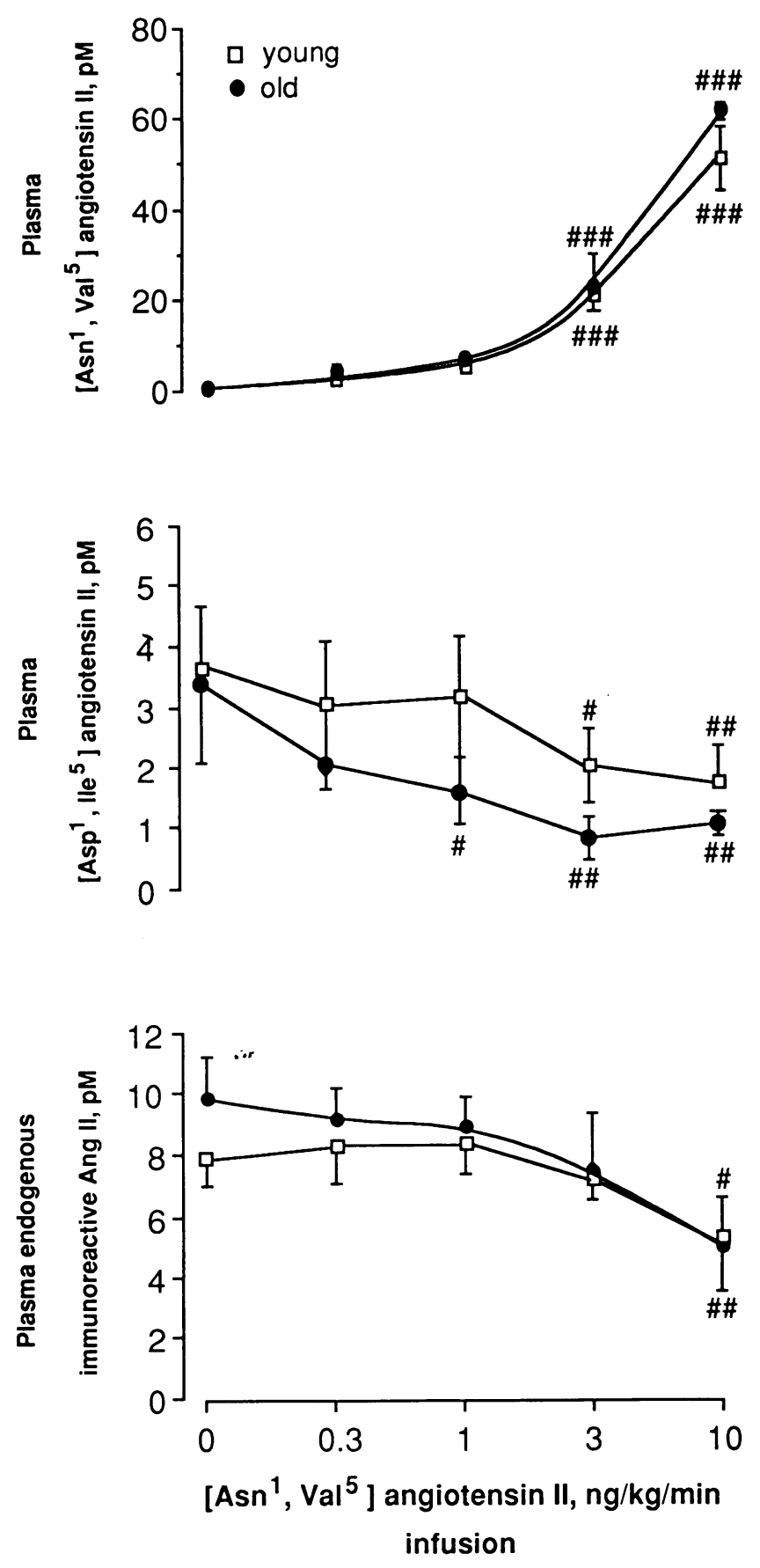

FIGURE 1. (upper panel) Hypertensin ([Asn $\left.{ }^{1}, \mathrm{Val}^{5}\right]$ angiotensin II), (middle panel) endogenous ANG II ([Asp $\left.{ }^{1}, I l e^{5}\right]$ angiotensin II), and (lower panel) immunoreactive endogenous ANG II plasma levels during Hypertensin infusion in young and old healthy subjects, mean $\pm S E M, \# \mathrm{P}<.05$, \#\# $\mathrm{P}<.01$, \#\#\# $\mathrm{P}<$ $.001, \mathrm{v}$ baseline. Decreasing concentrations of endogenous ANG II (middle and lower panels) indicate feedback suppression of renin by infused Hypertensin. Immunoreactive ANG II was obtained by conventional radioimmunological measurement using monoclonal antibodies but without prior HPLC. Immunoreactive Hypertensin was subtracted to estimate endogenous ir-ANG II.
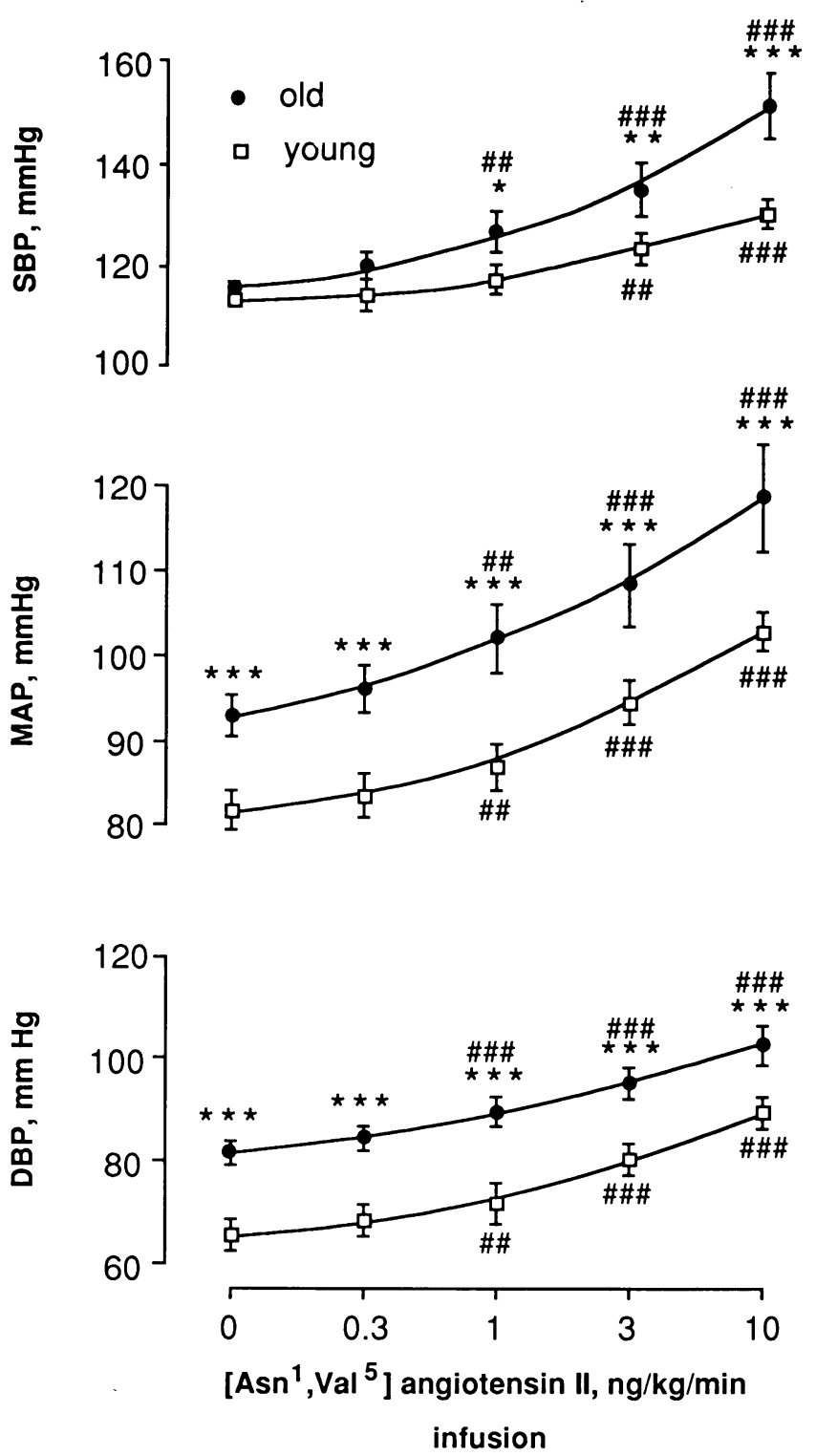

FIGURE 2. $S B P, D B P$ and $M A P$ response to Hypertensin $\left(\left[A s n^{1}, V^{2} l^{5}\right]\right.$ angiotensin II) infusion in young and old, mean \pm SEM. ${ }^{*} \mathrm{P}<.05,{ }^{* *} \mathrm{P}<.01,{ }^{* * *} \mathrm{P}<.001$, old compared to young; \#\# $\mathrm{P}<.01, \# \# \mathrm{P}<.001, \mathrm{v}$ baseline.

pertensin infusion did not differ significantly between the two groups. Heart rate fell during infusion in the young group with a significant difference from basal at the $10 \mathrm{ng} / \mathrm{kg} / \mathrm{min}$ infusion rate $(P<.05$, Figure 3$)$. There was a minimal and not significant decline in heart rate in the older subjects. When the change in heart rate was expressed as a percentage of basal heart rate there was a significant difference in response between young and old groups at the $10 \mathrm{ng} / \mathrm{kg} / \mathrm{min}$ infusion rate $(P<$ $.05)$ with a significantly blunted response in the old.

Hypertensin infusion resulted in significant increases in plasma aldosterone in both groups (Figure 4). The increment in plasma aldosterone was greater in the young than in the old subjects at infusion rates of 1,3 , 


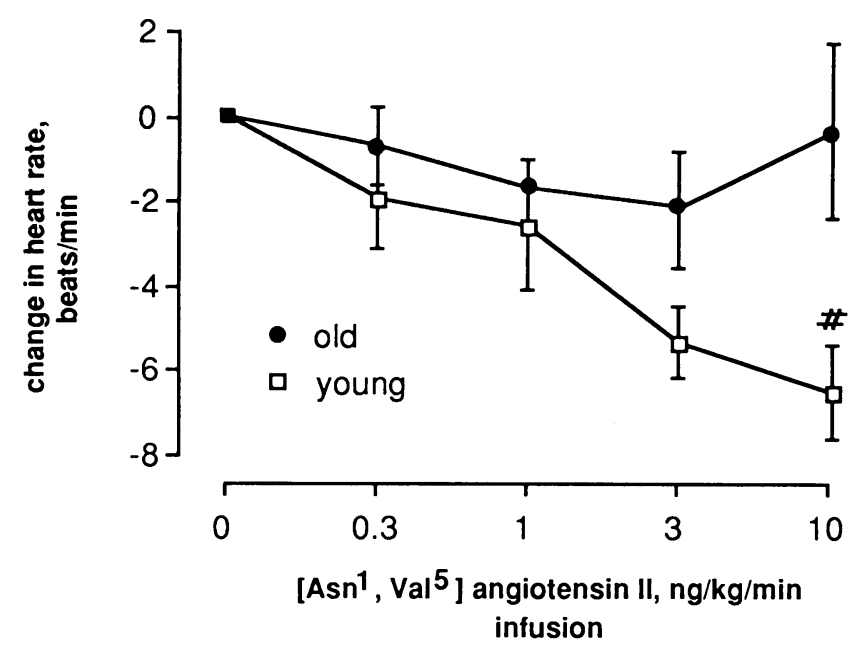

FIGURE 3. Heart rate response to Hypertensin ( $\left[\mathrm{Asn}^{1}, \mathrm{Val}^{5}\right]$ angiotensin II) infusion in young and old, mean $\pm S E M, \# P<.05 \mathrm{v}$ baseline.

and $10 \mathrm{ng} / \mathrm{kg} / \mathrm{min}$ (all $P<.001)$. Relative to the baseline levels, the absolute increases observed were on average 2 to 3 times greater in the young than in the old at these infusion rates. There was a significant negative correlation between $24 \mathrm{~h}$ urinary sodium and the aldosterone response to Hypertensin infusion for the young group ( $\mathrm{r}=-0.88, P=.01$ ) but not for the old group $(\mathrm{r}=-0.61, P=.14)$ or the two groups combined $(\mathrm{r}=$ $-0.49, P=.08)$.

\section{DISCUSSION}

The present study documents the effect of age on blood pressure, heart rate, endogenous ANG II and aldosterone responses to Hypertensin infusion. It is the first study to measure both endogenous and exogenous $(\mathrm{Hy}-$ pertensin) plasma ANG II levels attained during Hypertensin infusion. Hypertensin has been used for several decades for "angiotensin $\mathrm{II}^{\prime}$ infusions. It appears biologically equipotent to true ANG II despite the small differences in the molecular structure [ $\mathrm{Asn}^{1}, \mathrm{Val}^{5}$ instead of $\mathrm{Asp}^{1}$,Ile $^{5}$ sequence]. Conversion of Hypertensin into true human ANG II in vivo has never been observed and is very unlikely. Antisera differ if they are obtained in rabbits immunized with these two peptides and full cross-reaction is rare. ${ }^{\mathbf{2 3 , 2 4}}$ Similar plasma Hypertensin levels were found in both young and old groups during infusion and mean endogenous ANG II was lower in the elderly throughout the Hypertensin infusion although the difference was not significant. The increment in systolic pressure was greater in old than young in response to infusion, however, diastolic and mean arterial pressure responses were similar in both groups. Platelet ANG II receptor density was greater in old subjects. In contrast to pressor responsiveness, aldosterone responsiveness was markedly reduced in the old at all infusion rates except the initial low dose infusion.
In this study we have shown that it is possible to measure specifically and simultaneously exogenous and endogenous ANG II in plasma during Hypertensin infusion. We have demonstrated for the first time that endogenous ANG II concentrations decrease dose dependently with increasing levels of Hypertensin in both young and old healthy subjects. Even ir-ANG II (which is the sum of true ANG II and all the cross-reacting angiotensin peptides of conventional radioimmunoassays ${ }^{18}$ ) decreased during Hypertensin infusion (Figure 1) and thus also reflected the renin suppression induced by the infusion of Hypertensin. Unlike earlier investigations into the rate of angiotensin formation and metabolic clearance, we can now directly and accurately quantitate ANG II itself (both the generated endogenous ANG II and the accumulated infused Hypertensin) and we need no longer depend on the indirect evidence of plasma renin measurements.

There is the possibility, not addressed in previous studies, ${ }^{13,14,25}$ that age related changes in ANG II metabolism or clearance could give rise to differing levels of ANG II during infusion and account for differences in blood pressure or aldosterone responsiveness. In the present study, Hypertensin levels attained during infusion were similar in both groups and only marginally, and not significantly, higher in the old at the highest infusion rate. Endogenous ANG II levels, however, were consistently, although not significantly, lower in the older group throughout the Hypertensin infusion.

Interpretation of previous studies of pressor responsiveness to Hypertensin infusion in the elderly is complicated by the lack of information on screening of el-

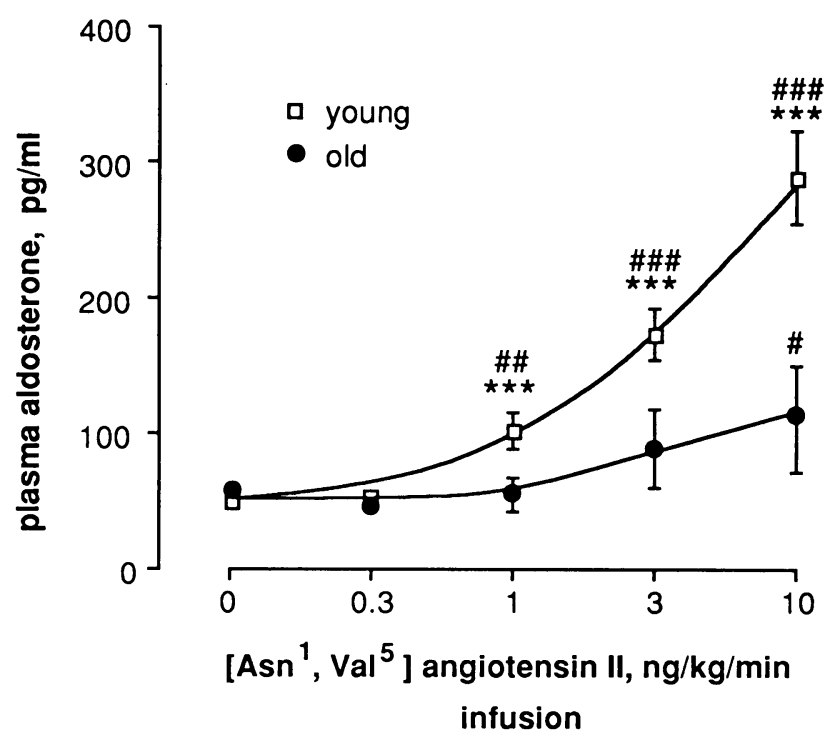

FIGURE 4. Aldosterone response to Hypertensin ([Asn $\left.{ }^{1}, \mathrm{Val}^{5}\right]$ angiotensin II) infusion in young and old, mean \pm SEM, $* * * \mathrm{P}<$ .001 , young compared to old; \# $\mathrm{P}<.05$, \#\# $\mathrm{P}<.01$, \#\# $\mathrm{P}<$ $.001, \mathrm{v}$ baseline. 
derly subjects to exclude disease $\mathbf{1 4 , 2 5}^{\mathbf{2}}$ and salt depletion of subjects. ${ }^{14}$ Furthermore, since plasma ANG II levels attained during infusion have not been monitored, ${ }^{13,14,25}$ a dose response relationship between pressor response and ANG II level cannot be assumed. In salt restricted subjects, greater increases in MAP have been observed in old than young in response to Hypertensin infusion. ${ }^{14}$ The data are difficult to compare with ours since our subjects were not salt restricted and furthermore, in that study, data are provided on MAP alone with no information on systolic responsiveness. In another investigation, less Hypertensin was required in elderly than young to raise DBP by $20 \mathrm{~mm} \mathrm{Hg.}{ }^{25}$ Although these two studies suggest increased pressor sensitivity to ANG II in the old, in the present investigation we observed an age related difference in systolic rather than diastolic responsiveness. Those who have found an enhanced blood pressure response to Hypertensin in the elderly have attributed it to the age related decline in plasma renin. ${ }^{14,25}$ A possible explanation for their findings would be an increase in vascular smooth muscle ANG II receptor density with age. In the present and a previous study, ${ }^{19}$ we have found platelet ANG II receptor density to be increased in the old and there was a positive, although not significant, correlation between receptor density and systolic blood pressure response to Hypertensin. If increased platelet receptor density reflects that of vascular smooth muscle, it provides a possible explanation for the increased systolic blood pressure response, however, this would not explain why diastolic pressure response was not also increased. The greater systolic response may simply reflect a nonspecific mechanism such as reduced vascular compliance or increased vascular stiffness in the older group. Alternatively, it may reflect the decline in baroreceptor sensitivity which occurs with age. ${ }^{26}$ The significantly blunted fall in heart rate during Hypertensin infusion in the old subjects is consistent with a decline in baroreceptor sensitivity with age. This is complicated, however, by the fact that baroreceptor sensitivity is altered during $\mathrm{Hy}$ pertensin infusion. ${ }^{27,28}$ In addition, infusion of Hypertensin, at least at very high doses, also exerts effects on the sympathetic nervous system ${ }^{29-32}$ and on the myocardium, ${ }^{33,34}$ thus, different responses with age at these sites cannot be excluded.

The age related fall in supine and ambulant plasma aldosterone is well established ${ }^{\mathbf{4}, 6,7,35}$ but the etiology is less clear. We have documented a severely impaired aldosterone response to Hypertensin in the older subjects, despite similar plasma Hypertensin levels. The blunted response occurred at all but the lowest infusion rate. In this context, it may be of interest that we also found a negative correlation between platelet ANG II receptor density and the aldosterone response to $\mathrm{Hy}$ pertensin. As discussed earlier, there were methodological problems with previous studies including a lack of plasma ANG II measurements, ${ }^{13,14,36}$ however, a significantly blunted aldosterone response to Hypertensin in the elderly was documented. ${ }^{14,36}$ In another study, the aldosterone response to corticotropin $(\mathrm{ACTH})$ was unchanged but the response to both Hypertensin and potassium was diminished in the elderly ${ }^{13}$ suggesting a generalized decline in aldosterone secretory response rather than a specific ANG II receptor defect. Different doses of Hypertensin may have been infused in young and elderly, however, since the investigators infused sufficient ANG II "to increase diastolic blood pressure by $20 \mathrm{~mm} \mathrm{Hg}$ for an hour." 13 In other studies, the aldosterone response to ACTH was either unchanged ${ }^{\mathbf{1 4}}$ or reduced $^{37}$ in the elderly. The aldosterone response to ANG II, potassium, and ACTH in suspensions of bovine adrenal zona glomerulosa cells is lower in cells from older animals. ${ }^{38}$ The reduced response to ANG II occurred despite similar zona glomerulosa ANG II receptor density in cells from young and old animals. Overall, therefore, the age related reduction in aldosterone response to Hypertensin appears to be part of a generalized reduction in aldosterone biosynthesis or secretory response with age.

In conclusion, Hypertensin infusion resulted in similar plasma Hypertensin levels in both young and old and a dose dependent decline in endogenous ANG II. Systolic rather than diastolic pressure response was increased in the elderly and the heart rate response was attenuated which may reflect diminished baroreceptor sensitivity with age. Aldosterone response to Hypertensin infusion was markedly blunted in the old.

\section{ACKNOWLEDGMENTS}

We wish to acknowledge the support of the Health Research Board (Ireland), the Research Committee of the Royal College of Surgeons in Ireland, and the Cardiovascular Research Foundation (Lausanne). We thank Theresa Walsh, Catherine Amstutz, and Irene Keller for their excellent technical assistance. We also thank Johannes Mann (Heidelberg, Germany) for advice in establishing the platelet ANG II receptor assay, Brian Faragher (Manchester, England) for statistical advice, and Ciba Geigy (UK) for the Hypertensin.

\section{REFERENCES}

1. Ziegler MG, Lake CR, Kopin IJ: Plasma noradrenaline increases with age. Nature 1976;261:333-353.

2. Duggan J, Kilfeather S, Lightman SL, et al: Plasma atrial natriuretic peptide concentration and platelet atrial natriuretic peptide binding site density in ageing and hypertension. Clin Sci 1991;81:509-514.

3. Haller B, Hansborg H, Shaw S, et al: Effects of posture and ageing on circulating atrial natriuretic peptide levels in man. J Hypertens 1987;5:551-556.

4. Crane MG, Harris JJ: Effect of ageing on renin activity and aldosterone excretion. J Lab Clin Med 1976;87:947959.

5. Noth R, Lassman M, Tan S, et al: Age and the renin-al- 
dosterone system. Arch Intern Med 1977;137:14141417.

6. Sambhi MP, Crane MG, Genest J: Essential hypertension: new concepts about mechanisms. Ann Intern Med 1973;79:411-424

7. Weidmann P, De Myttenaere-Bursztein S, Maxwell MH, De Lima J: Effect of ageing on plasma renin and aldosterone in normal man. Kidney Int 1975;8:325-333.

8. Kosunen $\mathrm{KJ}$, Pakarinen A: Correlations between plasma renin activity, angiotensin II and aldosterone. J Clin Endocrinol Metab 1978;47:665-666.

9. Aguilera G, Hauger RL, Catt KJ: Control of aldosterone secretion during sodium restriction: adrenal receptor regulation and increased adrenal sensitivity to angiotensin II. Proc Natl Acad Sci USA 1978;75:975-979.

10. Aguilera G, Catt KJ: Regulation of aldosterone secretion during altered sodium intake. J Steroid Biochem 1983; 19:525-530.

11. Gunther S, Gimbrone MA, Alexander RW: Regulation by angiotensin II of its receptors in resistance blood vessels. Nature 1980;287:230-232.

12. Moore TJ, Taylor T, Williams GH: Human platelet angiotensin II receptors: regulation by circulating angiotensin level. J Clin Endocrinol Metab 1984;58:778-782.

13. Saruta T, Suzuki A, Hayashi M, et al: Mechanism of age-related changes in renin and adrenocortical steroids. J Am Geriatr Soc 1980;28:210-214.

14. Takeda R, Morimoto S, Uchida K, et al: Effect of age on plasma aldosterone response to exogenous angiotensin II in normotensive subjects. Acta Endocrinol 1980;94: $553-558$

15. Nussberger J, Brunner D, Waeber B, Brunner H: True versus immunoreactive angiotensin II in human plasma. Hypertension 1985;7(suppl I):I1-I7.

16. Nussberger J, Brunner D, Waeber B, Brunner $H$ : In vitro renin inhibition to prevent generation of angiotensins during determination of angiotensin I and II. Life Sci 1988;42:1683-1688.

17. Nussberger J, Keller I, Waeber B, Brunner H: Angiotensin II measurement with high-affinity monoclonal antibodies. J Hypertens 1988;6(suppl 4):S424-S425.

18. Nussberger J, Brunner DB, Waeber B, Brunner H: Specific measurement of angiotensin metabolites and in vitro generated angiotensin II in plasma. Hypertension 1986;8:476-482.

19. Duggan J, Kilfeather S, O'Brien E, et al: Effects of aging and hypertension on plasma angiotensin II and platelet angiotensin II receptor density. Am J Hypertens 1992; 5:687-693.

20. Mann JFE, Sis J, Ritz E: ${ }^{125} \mathrm{I}-$ Angiotensin II binding to human blood cells. J Hypertens 1985;3:131 - 137.

21. Goodfriend TL, Ball DL: Angiotensin and renin, in Abraham GE (ed): Handbook of Radioimmunoassay. New York, Marcel Dekker Inc., 1977, pp 511-513.

22. Sumner DJ, Elliott HL, Vincent J, Reid JL: A pragmatic approach to the pressor dose-response as an index of vascular reactivity and adrenoceptor function in man. $\mathrm{Br}$ J Clin Pharmacol 1987;23:505-510.
23. Nussberger J, Matsueda GR, Re R, Haber E: Selectivity of angiotensin II antisera. J Immunol Methods 1983;56:8596.

24. Nussberger J: Erzeugung und Charakterisierung von Antikoerpern gegen Angiotensin II und deren Verwendung im radioimmunologischen Nachweis. Thesis, University of Zurich, 1974.

25. Meier A, Gubein U, Weidmann P, et al: Age related profile of cardiovascular reactivity to norepinephrine and angiotensin II in normal and hypertensive man. Klin Wochenschr 1980;58:1183-1188.

26. Gribbin B, Pickering TG, Sleight $P$, Peto R: Effect of age and high blood pressure on baroreflex sensitivity in man. Circ Res 1971;29:424-431.

27. Bagshaw RJ, Cox RH: Cardiovascular baroreceptor control during angiotensin-induced acute hypertension in the dog. J Hypertens 1988;6:699-709.

28. Garner MG, Phippard AF, Flecher PJ, et al: Effect of angiotensin II on the baroreceptor reflex control of heart rate in conscious baboons. Hypertension 1987;10:628634

29. Knape JT, Zweiten PA: Stimulation of vascular postsynaptic alpha-1 adrenoreceptors by noradrenaline released by angiotensin II in pithed rat preparations. Arch Int Pharmacodyn Ther 1987;290:64-76.

30. Peach MJ: Renin-angiotensin system: biochemistry and mechanisms of action. Physiol Rev 1977;57:313-370.

31. Schwieler JH, Kahan T, Nussberger J, Hjemdahl P: Influence of the renin-angiotensin system on sympathetic neurotransmission in canine skeletal muscle in vivo. Naunyn-Schmiedebergs Arch Pharmacol 1991;343: 166-172.

32. Szabo B, Hedler L, Schurr C, Starke K: Peripheral presynaptic facilitatory effect of angiotensin II on noradrenaline release in anaesthetised rabbits. J Cardiovasc Pharmacol 1990;15:968-975.

33. Freer RJ, Pappano AJ, Peach MJ, et al: Mechanism for the positive inotropic effect of angiotensin II on isolated cardiac muscle. Circ Res 1976;39:178-183.

34. Knape JT, Zweiten PA: Positive chronotropic activity of angiotensin II in the pithed normotensive rat is primarily due to activation of cardiac beta-1 adrenoreceptors. Naunyn-Schmiedebergs Arch Pharmacol 1988;338: 185-190.

35. Hegstad R, Brown RD, Jiang N, et al: Aging and aldosterone. Am J Med 1983;74:442-448.

36. Messerli FH, Weidmann P, De Chutel R, Maxwell MH: Responsiveness of plasma aldosterone: dependency upon basal secretory activity. Klin Wochenschr 1978; 56:719-726.

37. Morimoto $S$, Takeda $R$, Uchida $K$, et al: Reduced aldosterone secretory response to acute ACTH stimulation in sodium-restricted elderly subjects. J Am Geriatr Soc 1980;28:361-366

38. Potter CL, Goodfriend TL: Aldosterone production and hormone responsiveness in adrenal glomerulosa cells from cows of different ages. Gerontology 1987;33:7786. 